mountain stream, it is not hard to see how this epithet came to be associated with, and applied to, the stream itself, which is not regarded apart from its peculiar surroundings. The steep sides are, in fact, the characteristic feature of the ordinary Highland allt. The Reviewer.

\section{The Striped Hawk-Moth.}

With reference to the paragraph in NATURE of August ${ }_{1} 8$ (p. 389 ) on the striped hawk moth, on May 23 this year I found a specimen alive in a thick bed of lily-of-the-valley; it had just emerged, and had never flown. Warmwell is two miles from the sea as the crow flies; possibly the parent was a migrant, but the moth I found had passed through its metamorphosis in this country. The insect lived twelve hours after capture, and is now in the collection of $\mathrm{Mr}$. O. Picard-Cambridge, of Bloxworth.

Warmwell, Dorchester.

Rose Haig Thomas.

\section{Mountains and Mankind.}

I SHALL be obliged if you will allow me to correct the following errata in my address to Section $E$ of the British Association. For "Watson" and "Tokio" read Weston and Kobi (p. 429, column 2).

September 5 .

Douglas W. Freshfield.

[The errors occur in the copy of the address reprinted in NATURE.-EDitor.]

\section{BRITISH CHEMICAL EXHIBIT AT THE} ST. LOUIS EXHIBITION.

THE Royal Commission appointed to arrange the British exhibits for the St. Louis Exhibition have evidently, from the catalogue before us, carried out their difficult task with great care and in a most successful manner. We would that all catalogues were written in the extremely interesting and vivid style of the one to which we have referred. The products treated of in the catalogue are drawn up in alphabetical order, and at the end of the description of each substance, or group of substances, the names of the exhibitors are placed; the exhibitors are also arranged in alphabetical order at the end of the book.

The catalogue is written in the form of a history of the various manufacturing processes described therein. First and foremost we come to a most interesting and detailed account of the alkali industry, from the time of its inception to the present day. The reader is carried historically through the building up of the Le Blanc process - and the tragic fate of Le Blanc, its founder-the ammonia soda process, Chance's sulphur recovery process, and so on. Many details, which are not the common property of textbooks, as to the difficulties and failures and final success are included, which makes the narrative of exceptional interest. Before Solvay's time, several patents had been taken out which embodied the principles of his ammonia soda process, but he, unaware that others had worked upon the subject, experimented and patented the process, and we are shown in his own words what a blow he received on discovering that he was not the first in the field:-

"What was our astonishment in discovering.. I was no longer the inventor of the reaction and its industrial use had already tempted other investigators. It was a hard blow to me."

Here the narrator intervenes with the pertinent words: "Happily Solvay was young," and finally success attended his efforts. In so far as the ammonia soda process affects the British exhibits, we

1 Catalogue of British Exhibits; International Exbibition St. Lnuis, 1904. Department C, Liberal Aris; Chemical and Pharmaceutical Arts. 1904. Department C, Liberal Aris;
Issued by the Roya Commission.)

NO. I 8 I 9 , VOL. 7O] have to thank the indefatigable energy of Dr. Mond.

As a natural sequence the manufacture of sulphuric acid is treated of in the same section as that devoted to the alkali industry, and after being informed that sulphuric acid was first made by Ward at Richmond in 1740 , we are taken through the gradual development of the chamber process, and then introduced to the contact process, which may be said to have been originally founded on an experiment of Humphrey Davy in 1817 .

The section on alum is very interesting, and one notices how greatly manufacturers in this country are indebted to the acumen of Peter Spence, of Manchester.

One of the most interesting and suggestive sections is that dealing with the coal-tar products. In his report on the 1862 Exhibition, Hofmann spoke with sanguine eloquence of the bright prospects before the coal-tar colour industry in this country. The brilliant anticipations which Hofmann made for England have, alas! not been substantiated, for where we have sown others have reaped. The writer of this section endeavours to trace some of the causes which underlie the loss of the colour industry to England-such as the inadequate patent laws, want of research, which really means want of sufficient capacity for looking ahead.

To the electrochemical industry are devoted nine pages of the catalogue, which, commencing with an historical survey of the foundation of electrochemistry, passes on to deal with hypochlorites, chlorates, caustic alkali, and sodium. Then follows a description of the copper refining processes, and on p. 87 we are told that other metals, such as gold and silver, have been purified by electrolytic processes. As these have not been done in the United Kingdom, this is evidently in the nature of a hint to British electrochemists. A passing reference is made to the manufacture of calcium carbide, which, we regret to say, is at present not manufactured in this country.

We have only picked out a few of the subjects treated of in the catalogue; there are, of course, many others, such, for example, as explosives, the candle industry, soap, oils and colours, and so on.

There are also a good many scientific exhibits, among which may be noted Sir James Dewar's low temperature research exhibit, in which the complete plant, as employed at the Royal Institution for the production of liquid and solid hydrogen, is shown. Photographs of spectra by Mr. E. C. C. Baly, exhibits from the Lister Institute of Preventive Medicine, also a very complete exhibit from the Wellcome Research Laboratories, and many others which space forbids us to mention.

We do not know whether the catalogue is on sale in this country, but we recommend all interested in the manufacturing and scientific advancement of the country to endeavour to procure a copy; because the exhibits demonstrate that, in spite of the keen competition of Germany and other nations, Great Britain can still claim to be high up in brilliant achievements in chemical and allied sciences.

F. M. P.

\section{THE LIMNOLOGICAL STATIONS ON THE LAKE OF BOLSENA.}

TWO years ago the executive committee of the Italian Geographical Society determined to undertake the desirable work of preparing an exhaustive monograph on one of the lakes of Italy, and they very naturally selected the Lake of Bolsena for the purpose. Its situation within easy reach of Rome, 